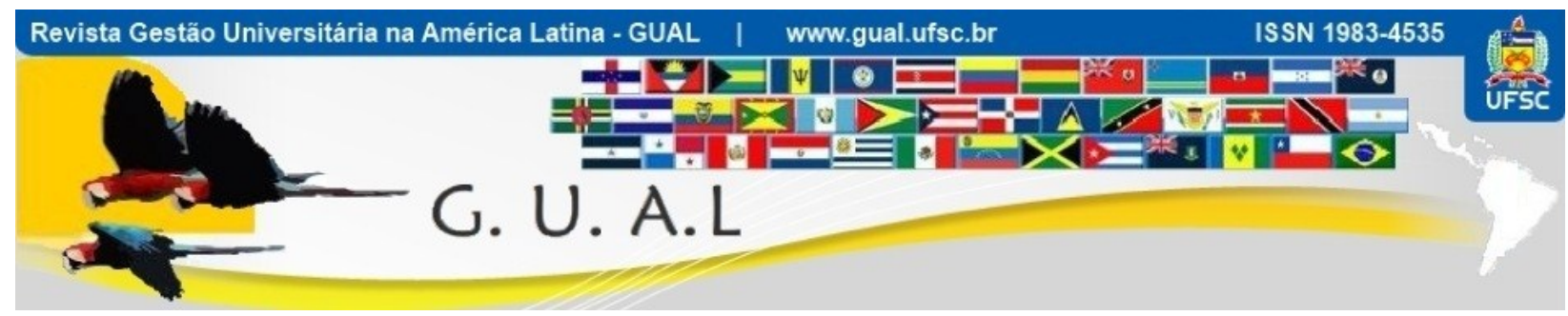

DOI: http://dx.doi.org/10.5007/1983-4535.2012v5n3p245

\title{
FATORES CRÍTICOS DE SUCESSO NA EDUCAÇÃO SUPERIOR BRASILEIRA
}

\author{
CRITICAL SUCCESS FACTORS IN BRAZILIAN HIGHER EDUCATION
}

Marcus Vinicius Andrade Lima, Doutor Universidade Federal de Santa Catarina - UFSC marcus.lima@gmail.com

Thiago Coelho Soares, Mestre Universidade do Sul de Santa Catarina - UNISUL thiago.soares@unisul.br

Luiz Henrique Herling Delbei, Mestre Universidade Federal de Santa Catarina - UFSC

lhherling@gmail.com

Claudia Cardoso Backer, Bacharel Universidade Federal de Santa Catarina - UFSC claudinha_backer@hotmail.com

Recebido em 17/setembro/2012

Aprovado em 06/dezembro/2012

Sistema de Avaliação: Double Blind Review

Esta obra está sob uma Licença Creative Commons Atribuição-Uso. 


\begin{abstract}
RESUMO
Este artigo tem a pretensão de verificar os fatores críticos de sucesso para cursos de graduação presenciais e a distância. Para isto procurou-se embasar teoricamente quanto as características da Educação a Distância (EaD) no Brasil e fatores críticos de sucesso na educação superior e em EaD. Esta pesquisa coleta um conjunto de informações que podem ser utilizadas gerencialmente em instituições que trabalham com educação a distância. Como resultado da pesquisa destaca-se o desafio de transformar os fatores chave de compra em atributos de valor que realmente são utilizados pelos compradores em seu processo de escolha. Como a escolha pode variar em função das preferências pessoais associadas aos produtos e serviços disponíveis, destaca-se a importância de um desempenho satisfatório nos critérios e excelência de regulação do ensino superior. Identificaram-se ao analisar os fatores críticos de sucesso identificados para os cursos a distância oito fatores comuns as diversas fontes pesquisadas. Quanto se trata de graduação presencial pode-se observar que os pontos comuns nas pesquisas realizadas por diversos autores identificaram treze pontos considerados importantes para o sucesso. Conclui-se que os coordenadores de cursos de graduação necessitam observar quais são os fatores críticos de sucesso para os cursos e procurar atendêlos para o sucesso organizacional.
\end{abstract}

Palavras-chave: Educação superior. Fatores críticos de sucesso. Fatores chaves de compra.

\begin{abstract}
This article purports to verify the critical success factors for undergraduate courses and distance. For that sought to explain theoretically how the characteristics of Distance Education (DE) in Brazil and critical success factors in higher education and distance education. This survey collects a set of information that can be used in managerial institutions working with distance education. As a result of research highlights the challenge of turning the key factors in purchase value attributes that are actually used by buyers in their selection process. As the choice may vary depending on personal preferences associated with the products and services available, highlights the importance of performing well on criteria of excellence and regulation of higher education. Were identified by analyzing the critical success factors identified for distance courses eight factors common to the various sources researched. When it comes to undergraduate classroom can be seen that the commonalities in research conducted by several authors identified thirteen points considered important for success. We conclude that the coordinators of undergraduate need to observe what are the critical success factors for courses and seek to serve them for organizational success.
\end{abstract}

Keywords: Higher education. Critical success factors. Key factors in purchase. 


\section{INTRODUÇÃO}

O interesse em se trabalhar com Educação a Distância (EaD), conforme Aretio (1996) não é um fenômeno recente. Observa-se que no século XVIII a Gazeta de Boston publicou um anúncio oferecendo ensino a distância, assim, já existiu a tentativa de se levar o conhecimento em cursos por correspondência. Com a melhora dos serviços de correio e agilização dos meios de transporte em meados do século XIX, percebe-se uma ação mais efetiva em direção às ofertas de cursos de EaD. Cinco exemplos dessa expansão podem ser destacados: um curso por ensino por correspondência publicado em 1833 na Suécia, a criação da primeira escola por correspondência pela fundação em Berlim no ano de 1856, a criação da Boston a Society to Encourage Study at Home em 1873, a criação do International Correspondence Institute em 1891, quando a Universidade de Wisconsin aceita a proposta de seus professores para organizar cursos por correspondência nos serviços de extensão universitária em 1891.

Já no final do século XIX e inicio do século XX, o ensino por correspondência ganhou proporções gigantescas nos EUA e na Europa. Isto aconteceu com a oferta de cursos pouco valor acadêmico. Isto pode ajudar a explicar a criação de uma visão de baixa qualidade atribuída aos cursos a distância. Porém como era de se esperar, o ensino por correspondência foi se aprimorando com o passar dos anos. Em 1969 surge na Inglaterra a UK Open University, por iniciativa do governo britânico (MAIA; MEIRELLES, 2005).

Já no Brasil, conforme Vianey (2003) os primeiros registros de EaD são de 1904, ofertando cursos técnicos por correspondência. O Instituto Monitor e o Instituto Universal Brasileiro consagraram este modelo. No que se refere as instituições de ensino superior (IES), a pioneira a oferecer cursos de graduação a distância foi a Universidade Federal do Mato Grosso do Sul. A metodologia consistia em material impresso e centros de atendimento com tutores. Já na segunda metade da década de 90, com o desenvolvimento da internet, as IES começaram a oferecer cursos à distância em maior quantidade. Esta escalada de cursos a distância foi medida por Maia e Meirelles (2005), observando que existiam mais de 50 IES no Brasil ofertando algum tipo de curso na modalidade EaD.

No Brasil as universidades privadas vêm procurando novas formas de se estruturar, principalmente em razão de novas realidades demográficas, políticas, econômicas e sociais. Esta nova estruturação pode oferecer serviços educacionais com diferencias, com qualidade e acessíveis, não apenas utilizando metodologias tradicionais de aprendizagem, mas também inovadoras, apoiadas em novas tecnologias. Além disto, novas políticas educacionais 
promovem a inclusão social por programas como a universidade para todos e o sistema de quotas. Desta forma, identificar fatores críticos de sucesso e fatores chave de compra passa a ser um assunto central entre os gestores de instituições universitárias, pois as estratégias estão direcionadas na efetivação de matrículas que promoverá a sobrevivência, a prosperidade acadêmica e financeira, direcionando o tamanho, a forma e as características dos discentes. (MEYER JR, LOPES, ZABLONSKY, 2006)

Desta forma este artigo pretende verificar os fatores críticos de sucesso para cursos de graduação presenciais e a distância.

\section{REGULAÇÃO DO ENSINO SUPERIOR}

Os critérios de excelência mais conhecidos no Brasil são os relativos ao MEC (Ministério da Educação) - IGC (Índice Geral de Cursos da Instituição) e ENADE (Exame Nacional de Desempenho de Estudantes), o Guia do Estudante da Editora Abril e Critérios de Excelência da Você S/A.

O Sistema Nacional de Avaliação da Educação Superior (Sinaes) foi criado pela Lei ${ }^{\circ}$ 10.861, de 14 de abril de 2004, o é formado por três componentes principais: a avaliação das instituições, dos cursos e do desempenho dos estudantes. Ele possui uma série de instrumentos complementares: auto-avaliação, avaliação externa, Enade, Avaliação dos cursos de graduação e instrumentos de informação (censo e cadastro). (MEC, 2009)

O Exame Nacional de Desempenho de Estudantes (Enade) tem o objetivo de aferir o rendimento dos alunos dos cursos de graduação em relação aos conteúdos programáticos, suas habilidades e competências. Calcula-se o conceito do curso pela média ponderada da nota padronizada dos concluintes no componente específico, da nota padronizada dos ingressantes no componente específico e da nota padronizada em formação geral (concluintes e ingressantes), possuindo estas, respectivamente, os seguintes pesos: $60 \%, 15 \%$ e $25 \%$. Assim, a parte referente ao componente específico contribui com $75 \%$ da nota final do curso, enquanto que a parte de formação geral contribui com 25\%. O conceito é apresentado em cinco categorias ( 1 a 5), sendo que 1 é o resultado mais baixo e 5 é o melhor resultado possível, na área. (MEC, 2009)

O Índice Geral de Cursos da Instituição (IGC) sintetiza, em notas de 1 a 5, a qualidade de todos os cursos, distribuídos em todos os campi e municípios em que atua. São levados em consideração conceitos para a graduação, como o Exame Nacional de Desempenho dos Estudantes (Enade) e as chamadas "variáveis de insumo", que consideram corpo docente, a 
infra-estrutura e o programa pedagógico. Além desses dados, também entra na média estabelecida pelo índice o conceito fixado pela Coordenação de Aperfeiçoamento de Pessoal de Nível Superior (Capes) para a pós-graduação. O resultado final, em valores contínuos, vão de 0 a 500. Em 2008, 21 IES conseguiram grau máximo. (MEC, 2009)

O Guia do Estudante da Editora Abril existe desde 1988 com o objetivo de avaliar a qualidade do ensino superior brasileiro. Em 2005, do total avaliado, 1.558 cursos superiores de todo o país receberam estrelas: 329 foram considerados excelentes e mereceram 5 estrelas; 550, muito bons e ganharam 4 estrelas; e 679, bons com 3 estrelas. Em 2006 o número de cursos estrelados aumentou em quase 50\%. Foram 2.280, de 355 escolas. Um crescimento que pode refletir uma melhora significativa na qualidade do ensino superior brasileiro. Os consultores avaliam os cursos classificando-os conforme os conceitos excelente (cinco estrelas), muito bom (quatro estrelas), bom (três estrelas), regular, ruim e "prefiro não opinar", com base no questionário preenchido pelos coordenadores e em seu notório saber. A conversão dos pareceres em estrelas é feita por uma média dos conceitos que cada curso recebeu. Como resultado final, cada curso avaliado recebeu um conceito, mas somente são divulgados aqueles que receberam três, quatro ou cinco estrelas. (GUIA DO ESTUDANTE, 2009).

Outro Critério de Excelência é medido pela Você SA. A nota atribuída é baseada em um levantamento realizado entre diretores de RH, alunos recém-formados, alunos veteranos, coordenadores de curso e professores. Cada grupo recebe um questionário com peso diferente na contagem final: $40 \%$ para o dos alunos recém-formados; $10 \%$ para o dos alunos antigos; $15 \%$ para o dos professores; $15 \%$ para o dos coordenadores de curso; e $20 \%$ para o dos diretores de RH. (VOCÊ S/A, 2009)

\subsection{FATOR CRÍTICO DE SUCESSO}

Os Fatores Críticos de sucesso (FCS) são áreas que tem o poder de influenciar o desempenho positivo de uma organização. Estas poucas áreas se obtiverem resultados satisfatórios poderão assegurar desempenho que promoverá competitividade e quiçá sucesso para a organização (ROCKART, 1979).

O conhecimento de quais são os FCS da organização podem auxiliar a gestão de uma organização. Estes fatores expressam caminhos que poderão servir de orientação para que a organização cumpra sua missão e objetivo. Essa possibilidade é verídica, pois os FCS têm a condição de oferecer suporte ao planejamento e a todas as suas etapas, bem como gerar 
assistência nas ações preferências de alocação de recursos, provendo informações aos gerentes que os ajudarão a administrar uma organização bem sucedida. (MALETZ, SIENDENBERG, 2007)

Os FCS têm diversas razões para ser implantado em uma organização. As principais são a aprimorar mapas mentais e auxiliar na definição das habilidades, tecnologias e conhecimentos essenciais para o alcance de um melhor desempenho. (OLIVEIRA, SANTOS, KALATZIS, 2007)

Conforme Seabra (2006) o ciclo de vida do produto, composto por introdução, crescimento, maturidade e declínio deve ser levado em consideração no momento de identificar os FCS de uma organização. Desta forma, a identificação dos FCS, em termos metodológicos, passa a ser uma relação matricial com o momento e lócus econômico em que se encontra o produto ou a empresa.

Oliveira, Santos e Kalatzis (2007) afirmam que existe uma vasta seleção de trabalhos na literatura nacional e internacional sobre FCS na educação, mas focando na Educação a Distância (EAD). Na sequência serão apresentados os FCS na educação superior.

\subsubsection{Fator crítico de sucesso na educação superior no Brasil}

A necessidade por informações e conhecimentos é cada vez mais constante. Assim, reconhece-se a relevância dos FCS como um importante instrumento de estratégia que os gestores de instituições de ensino superior possuem, pois pode identificar se os pontos fracos da IES são relevantes para o negócio, evitando que a empresa seja deficiente naquilo que é crítico para o sucesso do negócio (OLIVEIRA, SANTOS, KALATZIS, 2007)

Neste contexto apresentado, Mainardes, Deschamps, Domingues (2006) afirmam que atrair os discentes se tornou fundamental para o crescimento e a sobrevivência das IES. Diversas estratégias são adotadas pelas instituições de ensino superior com o objetivo de captar uma quantidade cada vez maior de alunos para seus diversos cursos.

Na sequência é apresentado os FCS em cursos presenciais e a distância.

\subsubsection{FCS em cursos presenciais}

Conforme Seabra (2006) os FCS para uma Universidade privada podem ser classificados em onze fatores. São eles: 1) Inovação como marca, 2) Gestão Financeira, 3) Participação dos Empregados, 4) Economia de Escopo, 5) Expansão Física e Incremento da Base de Clientes, 6) Política de Marketing, 7) Melhoria na Prestação de Serviço, 8) 
Tecnologia e Instalações como Referências de Qualidade, 9) Administração dos Recursos Internos, 10) A Influência do Fundador e 11) A Ação (ou inação) da Concorrência.

Já Mainardes, Deschamps, Domingues (2006) promoveram quarenta e dois fatores que são considerados críticos para os cursos de Administração. Os fatores foram analisados por alunos do curso de administração e podiam possuir notas de um a oito. O quadro a seguir identifica os fatores, ao grupo que pertence (pessoal, curso, IES, trabalho) e o escalonamento desenvolvido por média das respostas dos estudantes.

\begin{tabular}{|c|c|c|}
\hline Fator individual & $\begin{array}{l}\text { Fator } \\
\text { Geral }\end{array}$ & Nota \\
\hline Qualidade da faculdade/universidade no ensino/aprendizado & Curso & 6 \\
\hline Infra-estrutura e instalações da faculdade/universidade & IES & 5,5 \\
\hline Empregabilidade do curso escolhido & Trabalho & 5,2 \\
\hline Avaliação do MEC do curso oferecido pela instituição de ensino & IES & 5,1 \\
\hline Percepção da qualidade do serviço prestado pela instituição de ensino & IES & 5,1 \\
\hline Reputação do curso e da faculdade/universidade & Trabalho & 5,1 \\
\hline Horários disponíveis de aulas no curso escolhido & Curso & 5 \\
\hline Satisfação de bacharéis com a faculdade/universidade & Curso & 5 \\
\hline $\begin{array}{l}\text { Imagem da instituição de ensino oferecida por alunos que já estão cursando uma } \\
\text { graduação }\end{array}$ & IES & 5 \\
\hline Aceitação da instituição de ensino pelo mercado de trabalho & Trabalho & 5 \\
\hline Cursos oferecidos pela faculdade/universidade & IES & 4,9 \\
\hline Compromisso da faculdade/universidade com o serviço prestado & IES & 4,8 \\
\hline Valor do diploma da faculdade/universidade no mercado de trabalho & Trabalho & 4,8 \\
\hline $\begin{array}{l}\text { Visibilidade e reconhecimento da instituição de ensino e do curso escolhido perante } \\
\text { sociedade }\end{array}$ & Trabalho & 4,8 \\
\hline Imagem criada por você da faculdade/universidade & Pessoal & 4,8 \\
\hline Campanha de marketing da faculdade/universidade & IES & 4,6 \\
\hline $\begin{array}{l}\text { Geração, aceitação e implementação na instituição de ensino de novas idéias, } \\
\text { processos, produtos ou serviços }\end{array}$ & IES & 4,6 \\
\hline $\begin{array}{l}\text { Regulamentação e adaptação de espaços para uso dos alunos, funcionários e } \\
\text { comunidade }\end{array}$ & IES & 4,6 \\
\hline Tradição e status da instituição de ensino & Trabalho & 4,6 \\
\hline Visão da instituição com relação ao desenvolvimento sustentável & Trabalho & 4,6 \\
\hline $\begin{array}{l}\text { Comentários de satisfação ou insatisfação dos alunos atuais com o curso e com a } \\
\text { instituição }\end{array}$ & IES & 4,5 \\
\hline $\begin{array}{l}\text { Práticas administrativas (vestibular, processo seletivo, matrículas, apoio ao estudante) } \\
\text { da instituição de ensino }\end{array}$ & IES & 4,5 \\
\hline Propensão da instituição de ensino a inovação & IES & 4,5 \\
\hline Opinião da comunidade com relação a instituição de ensino & Trabalho & 4,5 \\
\hline $\begin{array}{l}\text { Participação da faculdade/universidade em assuntos atuais (crescimento sustentável, } \\
\text { responsabilidade social, meio ambiente) }\end{array}$ & Trabalho & 4,5 \\
\hline Preocupação da faculdade/universidade com seus alunos & IES & 4,4 \\
\hline Proximidade da faculdade/universidade de sua casa ou trabalho & Pessoal & 4,4 \\
\hline Atmosfera positiva entre pessoas e ambientes na instituição de ensino & IES & 4,3 \\
\hline $\begin{array}{l}\text { Compromisso da instituição de ensino com a comunidade e relações com sociedade e } \\
\text { natureza }\end{array}$ & IES & 4,2 \\
\hline Segurança no campus da faculdade/universidade & IES & 4,2 \\
\hline Satisfação com a instituição de ensino de parentes & Pessoal & 4,2 \\
\hline
\end{tabular}




\begin{tabular}{|l|c|c|}
\hline Influência de familiares, amigos, colegas de trabalho & Pessoal & 4,1 \\
\hline Coerência e interação entre teoria e prática no curso escolhido & Curso & 4 \\
\hline Práticas pedagógicas (aulas e apoio a aprendizagem) & Curso & 4 \\
\hline Abertura da instituição de ensino para a participação democrática & IES & 4 \\
\hline Atendimento dos funcionários da faculdade/universidade & IES & 4 \\
\hline Taxas de aprovação em exames de alunos do curso escolhido & Trabalho & 4 \\
\hline Atividades em sala de aula e fora dela de simulação da vida real & Curso & 3,5 \\
\hline Valor da mensalidade & IES & 3,5 \\
\hline Corpo de professores do curso escolhido & Curso & 3 \\
\hline Experiências anteriores na instituição de ensino & Pessoal & 3 \\
\hline $\begin{array}{l}\text { Ligação sentimental com a faculdade/universidade (estudou nela anteriormente, } \\
\text { familiares e/ou amigos estudaram na instituição, etc.) }\end{array}$ & Pessoal & 3 \\
\hline
\end{tabular}

Quadro 1 Classificação individual dos 42 fatores identificados para IES

Fonte: Mainardes, Deschamps, Domingues, 2006

No Brasil atualmente o ambiente de transformações e de competição por um número maior de alunos e por prestígio, que está presente no setor da educação superior, é incompatível com a gestão de matrículas que é praticada hoje, pois esta é uma prática incipiente, dispersa e desintegrada. A universidade americana DePaul University poderá ser usada como referência aos gestores das IES comunitárias brasileiras, que vem sendo pressionadas a melhorar o seu desempenho. Desta forma a gestão de matrículas torna-se um FCS para essas organizações. (MEYER JR, LOPES, ZABLONSKY, 2006)

Cislaghi, Luz Filho (2006) analisam as estratégias das universidades públicas e privadas. No quadro 2 é apresentada uma comparação as duas. Pode-se ressaltar que para as instituições privadas os fatores críticos de sucesso identificados foram cinco: taxa de crescimento, lucro, participação de mercado, exclusividade e tecnologia avançada.

\begin{tabular}{|l|l|l|}
\hline \multicolumn{1}{|c|}{ Atributo Estratégico } & \multicolumn{1}{|c|}{ Setor Privado } & \multicolumn{1}{c|}{ Setor Público } \\
\hline Objetivo estratégico geral & Competitividade & Efetividade da missão \\
\hline Objetivo financeiro geral & $\begin{array}{l}\text { Lucro; crescimento; participação no } \\
\text { mercado }\end{array}$ & Redução de custos; Eficiência \\
\hline Valores & $\begin{array}{l}\text { Inovação; criatividade; disposição; } \\
\text { reconhecimento }\end{array}$ & $\begin{array}{l}\text { Comprometimento com o público; } \\
\text { honestidade; justiça }\end{array}$ \\
\hline Resultado desejado & Satisfação do cliente & Satisfação do cliente \\
\hline Interessados & Acionistas; proprietários; clientes & $\begin{array}{l}\text { Contribuintes; inspetores; } \\
\text { Legisladores }\end{array}$ \\
\hline \multirow{2}{*}{ Prioridades do orçamento } & Demanda dos clientes & $\begin{array}{l}\text { Lideranças; legisladores; } \\
\text { Planejadores }\end{array}$ \\
\hline \multirow{2}{*}{ Justificativa para o sigilo } & $\begin{array}{l}\text { Proteção ao capital intelectual; direitos } \\
\text { autorais }\end{array}$ & Segurança nacional \\
\hline \multirow{2}{*}{ Fatores-chave do sucesso } & $\begin{array}{l}\text { Taxa de crescimento; lucros; participação } \\
\text { no mercado }\end{array}$ & Melhores práticas gerenciais \\
\cline { 2 - 3 } & Exclusividade & Isonomia; economia de escala \\
\cline { 2 - 3 } & Tecnologia avançada & Tecnologia padronizada \\
\hline
\end{tabular}

Quadro 2 Diferenças entre as estratégias do setor público e do setor privado.

Fonte: Cislaghi, Luz Filho (2006) 
Gonçalves, Colauto, Beuren (2005) apontam fatores críticos de sucesso de acordo com os três níveis da organização, o estratégico, administrativo e pedagógico. Assim existiu um agrupamento dos FCS de uma instituição de ensino superior. A determinação destes FCS se deu por meio da percepção dos dirigentes da instituição.

\begin{tabular}{|l|}
\hline \multicolumn{1}{|c|}{ NÍVEL ESTRATÉGICO } \\
\hline Localização geográfica \\
\hline Tradição da instituição \\
\hline Imagem da organização \\
\hline Garantia de reconhecimento do curso \\
\hline Valor de mensalidade menor que a concorrência \\
\hline Parceria com outra instituição de ensino superior de reconhecimento nacional \\
\hline \multicolumn{2}{|c|}{ NÍVEL ADMINISTRATIVO } \\
\hline Infra-estrutura NíVEL PEDAGÓGICO \\
\hline Campanha publicitária periódica \\
\hline Serviços de secretaria e de pessoal \\
\hline \\
\hline Qualificação do corpo docente \\
\hline Atualização do corpo docente \\
\hline Interação da coordenação com o corpo discente \\
\hline Integração dos alunos com a instituição \\
\hline Metodologia aplicada à realidade do mercado de trabalho \\
\hline
\end{tabular}

Quadro 3 Fatores críticos de sucesso na percepção da instituição de ensino Fonte: Gonçalves, Colauto, Beuren (2005)

Pode-se observar que os pontos comuns nas pesquisas realizadas por diversos autores nos levam a identificação de treze pontos considerados importantes para o sucesso de um curso de ensino presencial brasileiro.

\begin{tabular}{|l|}
\hline Localização geográfica (Proximidade da faculdade/universidade de sua casa ou trabalho) \\
\hline Tradição da instituição (Tradição e status da instituição de ensino) \\
\hline Imagem da organização (Reputação do curso e da faculdade/universidade) \\
\hline $\begin{array}{l}\text { Garantia de reconhecimento do curso (Avaliação do MEC do curso oferecido pela instituição } \\
\text { de ensino) }\end{array}$ \\
\hline Valor de mensalidade menor que a concorrência (Valor da mensalidade) \\
\hline Infra-estrutura (Infra-estrutura e instalações da faculdade/universidade) \\
\hline Campanha publicitária periódica (Campanha de marketing da faculdade/universidade) \\
\hline Serviços de secretaria e de pessoal (Atendimento dos funcionários da faculdade/universidade) \\
\hline Qualificação do corpo docente (Qualidade da faculdade/universidade no ensino/aprendizado) \\
\hline Atualização do corpo docente (Corpo de professores do curso escolhido) \\
\hline Interação da coordenação com o corpo discente \\
\hline Integração dos alunos com a instituição \\
\hline $\begin{array}{l}\text { Metodologia aplicada à realidade do mercado de trabalho (Atividades em sala de aula e fora } \\
\text { dela de simulação da vida real) }\end{array}$ \\
\hline
\end{tabular}

Quadro 4 Fatores críticos de sucesso para cursos de ensino presencial Fonte: Elaborado pelos autores 
Na seqüência serão apresentados os fatores críticos de sucesso para cursos de ensino a distância.

\subsubsection{FCS em EaD}

Ferreira (2001) já abordava no início da década que existem três questões que podem ser importantes. São elas: o tipo de conhecimento, em que profundidade e para quem é oferecido o serviço. Estes são fatores crítico de sucesso para as organizações que buscam a adoção de novas tecnologias, ou seja, querem trabalhar com EaD.

$\mathrm{O}$ EaD foi e será adotada por muitas das mais conceituadas instituições de educação. Desta forma, vários FCS relacionados com adoção deste tipo de educação devem ser cuidadosamente avaliados antes, durante, e depois de qualquer implantação de EaD. A adoção da tecnologia de e-aprendizagem é um processo complicado de estabelecimento e desenvolvimento de um sistema de tecnologia de informação integrado. São fatores que podem auxiliar universidades e professores a adotar tecnologias de e-aprendizagem de maneira eficiente e efetiva. Os FCS para desenvolvimento de e-learning em universidades podem ser agrupados em quatro categorias: Professor/tutor, Estudante, Tecnologia da Informação e Suporte da universidade (SELIM, 2007).

\begin{tabular}{|c|c|}
\hline Grupo & FCS \\
\hline \multirow{13}{*}{$\begin{array}{l}\text { Características do } \\
\text { Professor/tutor }\end{array}$} & O professor está entusiasmado com a classe docente \\
\hline & O estilo de apresentação do professor gera interesse \\
\hline & O professor é amigável com os estudantes \\
\hline & O professor tem um genuíno interesse nos estudantes \\
\hline & Estudantes sentiram-se acolhidos na procura de aconselhamento / ajuda \\
\hline & O professor incentiva interação aluno \\
\hline & O professor trata efetivamente as unidades \\
\hline & O professor explica como utilizar os componentes do e-learning \\
\hline & O professor faz questão de que os alunos utilizem as unidades de e-learnings \\
\hline & O professor motiva os alunos a fazer perguntas \\
\hline & O professor incentiva os alunos a participar nas aulas \\
\hline & O professor incentiva e motiva os alunos a utilização de e-learning \\
\hline & O professor está ativo no ensino de disciplinas do curso via e-learning \\
\hline \multirow{7}{*}{$\begin{array}{l}\text { Características do } \\
\quad \text { estudante }\end{array}$} & O e-learning encoraja o aluno a pesquisar mais do que nos métodos tradicionais \\
\hline & $\begin{array}{l}\text { O e-learning encoraja o aluno participar mais ativamente na discussão do que os } \\
\text { métodos tradicionais }\end{array}$ \\
\hline & O aluno gosta de usar computadores pessoais \\
\hline & O aluno usa computadores pessoais para trabalhar e jogar \\
\hline & $\begin{array}{l}\text { O aluno estava confortável com a utilização do PC e de aplicações de software } \\
\text { antes que assumiu o e-learning baseado cursos }\end{array}$ \\
\hline & $\begin{array}{l}\text { Experiência anterior em usar o PC e me ajudou em aplicações de software de e- } \\
\text { learning baseado cursos }\end{array}$ \\
\hline & O aluno não está intimidados em cursar Ead \\
\hline
\end{tabular}




\begin{tabular}{|c|c|}
\hline & O aluno aprende melhor pela absorção (sentado e absorver) \\
\hline & O aluno aprende melhor pela construcão (por participacão e contribuição) \\
\hline & O aluno aprende melhor por construção do que por absorção \\
\hline & O aluno só lê as mensagens no grupo de discussão \\
\hline & O aluno lê, bem como participar no grupo de discussão \\
\hline & O professor iniciou a maior parte das discussões \\
\hline & Os alunos iniciaram a maior parte das discussões \\
\hline & O professor participou ativamente na discussão \\
\hline & $\begin{array}{l}\text { O aluno encontrou as instruções sobre a utilização do e-learning e seus } \\
\text { componentes de forma clara }\end{array}$ \\
\hline & O aluno achou o conteúdo do curso suficiente e relacionado aos objetivos \\
\hline & O aluno achou fácil compreender a estrutura do e-learning e seus componentes \\
\hline & O aluno achou fácil navegar através do Blackboard / webcurso \\
\hline & Os componentes do e-learning estavam disponíveis o tempo todo \\
\hline & Os materiais didáticos foram colocadas on-line em tempo oportuno \\
\hline & O aluno percebeu o design dos componentes do e-learning bons \\
\hline \multirow{13}{*}{ Tecnologia } & No campus o acesso a internet é fácil \\
\hline & Os alunos não experimentaram problemas enquanto navegam \\
\hline & A velocidade da navegação era satisfatória \\
\hline & Globalmente, o site foi fácil de usar \\
\hline & A informação foi bem estruturada / apresentada \\
\hline & O aluno achou que a tela design agradável \\
\hline & O aluno poderia interagir com colegas através da web \\
\hline & $\mathrm{O}$ aluno poderia facilmente entrar em contato com o instrutor \\
\hline & O aluno pode usar qualquer PC na universidade utilizando a mesma conta e senha \\
\hline & O aluno pode usar o computador de laboratórios para a prática \\
\hline & O aluno pode confiar na rede de computadores \\
\hline & O aluno pode registrar cursos on-line utilizando Banner \\
\hline & Globalmente, a infra-estrutura da tecnologia da informação é eficiente \\
\hline \multirow{5}{*}{ Suporte } & O aluno pode acessar o site da biblioteca central e procure por materiais \\
\hline & O aluno pode obter suporte técnico a partir de técnicos \\
\hline & O aluno vê o apoio do e-learning UAEU como bom \\
\hline & Há um número suficiente de computadores para uso e prática \\
\hline & apoio imprimir o manual e materiais facilmente \\
\hline
\end{tabular}

Quadro 5 FCS para EaD.

Fonte: Selim (2007)

Selim (2007) utilizou uma amostra de 900 estudantes com o intuito de identificar e medir os FCS para o EaD. Em sua pesquisa identificou que todos os indicadores da atitude do professor relacionados ao controle da tecnologia indicaram altos níveis de importância. A motivação do estudante e a competência técnica mediram níveis elevados de validade também. Na dimensão tecnológica, o fator mais crítico foi a disponibilidade de laboratórios de computadores para atividades. O suporte de universidade não foi limitado a ajuda técnica e resolução de problemas, mas incluía biblioteca e disponibilidade de prestar informações. Vale ressaltar que o estudo especificou os fatores críticos que afetam adoção de tecnologia de $\mathrm{EaD}$ por universidades na perspectiva dos estudantes. 
Os pesquisadores Masrom, Zainon e Rahiman (2008) desenvolveram pesquisa semelhante, porém analisando apenas dois grupos de FCS: Tecnologia da Informação e Suporte da universidade.

$\mathrm{Na}$ dimensão tecnológica, foram encontrados dois fatores críticos de sucesso: a velocidade de navegação e a tranqüilidade da navegabilidade do website. Estas informações são compatíveis com pesquisas anteriores. Por outro lado, na infra-estruturar os resultados mostraram que a confiança de rede de computador a estudantes foi o fator mais importante. A disponibilidade de laboratórios de computadores a estudantes veio em segundo lugar. Esses informação são opostas ao estudo anterior conduzido por Selim (2007). Selim descobriu que a disponibilidade de laboratórios de computador foi o fator mais crítico na categoria de tecnologia. Isto pode ter ocorrido por diferenças de ambientes pesquisados. Para a dimensão de suporte institucional a disponibilidade de assistente técnico foi o fator de êxito mais relevante. Esta informação é apoiada por estudos prévios. (MASROM, ZAINON E RAHIMAN, 2008)

Masrom, Zainon e Rahiman (2008) apontam que os resultados de seu estudo evidenciam que seja necessário o conhecimento dos FCS tecnológicos e de suporte por parte dos gestores das universidades. Além disto, o estudo indica que os fatores de suporte tecnológicos e suporte institucionais desempenham o papel importante no uso do EaD. (MASROM, ZAINON E RAHIMAN, 2008)

Oliveira, Santos e Kalatzis (2007) adotam cinco grupos de Fatores Críticos de Sucesso, sendo: Técnico; Mercadológico e Negócios; Econômico e Financeiro; Político e Jurídico. Detalham-se a seguir tais FCS.

Com o FCS técnico pretende conhecer o comportamento no que tange a questões técnicas como, os instrumentos de apoio a construção dos projetos de EaD. No desenvolver destes projetos estão envolvidos procedimentos que exigem o domínio técnico de diversas tecnologias, de contratos (jurídicos), financeiros e políticos. As questões relevantes: avaliação das necessidades dos usuários, montagem do projeto, desenho do projeto e dos contratos, a avaliação de projetos, a coordenação e gestão de projetos, entre outras. Com o FCS mercadológico e negócios é possível conhecer o que está acontecendo com o desempenho do projeto. Normalmente abrange questões que tangem o mercado da $\mathrm{EaD}$, tais como: usuários, nível de serviços, a oferta, a demanda, os aspectos macroeconômicos que influenciam nos negócios, os atores envolvidos, como os, as decisões governamentais, a política de investimentos, entre outros. Com o FCS econômico e financeiro busca-se identificar questões 
referentes ao comportamento e tendências relacionadas a economia e financeira, tais como: política econômica do governo, indicadores econômico e financeiro, mercado financeiro, política de risco, estrutura de custos, entre outros. Assim, pode-se permitir a adequabilidade do projeto, como, garantia do melhor desempenho econômico possível do projeto; a manutenção permanente do equilíbrio financeiro; e uma política equilibrada de endividamento. Com o FCS jurídico pode-se identificar aspectos institucionais e jurídicos mais relevantes, as legislações, as regulamentações, as alterações na legislação, entre outras. Pode-se dispor de informações referentes às questões que afetam o desempenho dos projetos, como as questões jurídico-institucionais, as garantias contratuais, os direitos e deveres dos consumidores, a defesa da concorrência, etc. Com o FCS político tem-se informações de mecanismos que poderão viabilizar os investimentos, a contenção das crises políticas, entre outras. Com esta análise pode-se saber o que está acontecendo com este fator e como esta situação afeta o desempenho do projeto. (OLIVEIRA, SANTOS, KALATZIS, 2007)

Ferreira (2001) identifica que no campo do ensino é salutar considerar o ponto de vista de quem busca o conhecimento, características sobre aprendizado a distância, as categorias específicas de recursos de aprendizagem disponíveis, os custos associados com o desenvolvimento de projetos de educação à distância. Assim, o autor discute como se pode achar um melhor caminho para a inserção do ensino a distância nas Escolas de Negócios.

\begin{tabular}{|c|c|}
\hline Categoria & Fator Crítico de Sucesso \\
\hline \multirow{5}{*}{$\begin{array}{l}\text { O ponto de vista de } \\
\text { quem busca o } \\
\text { conhecimento }\end{array}$} & $\begin{array}{l}\text { A experiência deve parecer o máximo possível personalizada? Ou deve adotar o } \\
\text { formato presencial de um padrão para todos? }\end{array}$ \\
\hline & Deve se buscar satisfazer estilos de aprendizagem diferentes? \\
\hline & $\begin{array}{l}\text { Deve o ensino deve ser baseado em atividades, é preciso fomentar a interação } \\
\text { entre participantes de cursos baseados em tecnologias de ensino a distância? }\end{array}$ \\
\hline & $\begin{array}{l}\text { Depois de uma atividade reflexiva é importante que os clientes possam discutir } \\
\text { com outros ou que possam elaborar perguntas? }\end{array}$ \\
\hline & $\begin{array}{l}\text { Quem aprende precisa saber o propósito das atividades que lhes são } \\
\text { recomendadas? }\end{array}$ \\
\hline \multirow{11}{*}{$\begin{array}{c}\text { Características } \\
\text { sobre aprendizado a } \\
\text { distância }\end{array}$} & flexibilidade: \\
\hline & pode ser customizado, de forma a atender o alcance do usuário; \\
\hline & $\begin{array}{l}\text { permite aprendizagem individual - provê um ambiente de aprendizado } \\
\text { individualizado; }\end{array}$ \\
\hline & permite ao usuário controle sobre o que vai aprender; \\
\hline & é uma forma de aprendizado não competitiva; \\
\hline & interativo, permite seguir aprendendo; \\
\hline & o usuário recebe feedback imediato; \\
\hline & permite constante atualização; \\
\hline & as mudanças podem ser feitas em tempo real; \\
\hline & ensino de conceitos abstratos pode ser feito através de instrumentos lúdicos. \\
\hline & programas de simulação substituem laboratórios, risco de experimentar, reduz a \\
\hline
\end{tabular}






Quadro 6 Fatores Críticos de Sucesso para a inserção do ensino a distância nas Escolas de Negócios. Fonte: Adaptado de Ferreira (2001)

Ao analisar todos os fatores críticos de sucesso identificados para os cursos a distância, foi possível observar os seguintes fatores comuns, expressos no quadro a seguir.

\begin{tabular}{|l|}
\hline Flexibilidade no Estudo (flexibilidade de horários e locais) \\
\hline Acolhimento do aluno pelo professor (relação aluno/professor) \\
\hline Usabilidade do Sistema (facilidade em utilizar as tecnologias) \\
\hline Tecnologia (suporte tecnológico para resolução de dúvidas) \\
\hline Segurança (confiabilidade nas informações) \\
\hline Interação (relação entre os alunos no espaço virtual) \\
\hline Qualidade do Curso (Fator não identificado na pesquisa, mas considerado importante no cenário atual \\
\hline
\end{tabular}


da educação a distância)

Reconhecimento pelo MEC (Fator não identificado na pesquisa, mas considerado importante no cenário atual da educação a distância)

Quadro 7 Fatores Críticos de Sucesso para EaD.

Fonte: Elaborado pelos Autores

Assim, Seabra (2006) afirma que os FCS são áreas de atividades que devem receber a atenção constante dos gestores das instituições de ensino superior.

\subsubsection{Metodologias para implantação e identificação de FCS}

$\mathrm{Na}$ metodologia desenvolvida por Seabra (2006) o processo metodológico consistiu em entrevistar atores proeminentes, ou seja, pessoas que julgava importante, composto por um conjunto de 12 especialistas. Utilizou-se questionário estruturado e contato direto com os respondentes, procurando confirmar e graduar a importância dos FCS(s) que marcaram a ascensão da Estácio, no período 1970-2000. Esta metodologia está constante de dois passos: 1. A proposição de $\operatorname{FCS}(\mathrm{s})$ por especialistas, a partir de vetores inspirados na análise porteriana; 2. O julgamento, por especialistas respondentes, da efetiva participação dos fatores propostos para o sucesso da organização. Na sequência os dados foram tratados aplicando-se a Lógica Fuzzy para construir uma listagem que caracterizasse a importância real dos FCS(s). Os dados foram tratados por ferramental proveniente da estatística descritiva, por determinação de freqüência. Segundo o autor todos os onze fatores analisados foram considerados relevantes.

Já Mainardes, Deschamps, Domingues (2006) analisaram 42 fatores que julgavam importantes para o sucesso da organização. Os fatores foram analisados por alunos do curso de administração de duas universidades do norte catarinense. Os alunos podiam atribuir peso de um a oito, sendo um de sem relevância e oito relevância máxima. Posteriormente os dados foram tratados estatisticamente para identificar o valor a ser atribuído para cada FCS. Segundo os autores os FCS que tiverem média superior a quatro são relevantes para a organização. Assim, dos 42 fatores identificados, 37 foram considerados relevantes.

Nas pesquisas desenvolvidas para a educação a distância, Selim (2007) entrevistou 900 estudantes, dos quais 538 foram utilizados para a montagem do relatório. Realizou análise estatística para verificar quais são os fatores mais importantes na ótica dos respondentes. 


\subsubsection{Fator chave de compra}

Os fatores-chave de compra são derivados dos fatores críticos de sucesso. Entende-se por fatores chave de compra o conjunto de fatores e o seu peso relativo que o consumidor/cliente utiliza para selecionar um fornecedor/produto. $\mathrm{O}$ fator chave de compra pode ser utilizado em quatro formas diferentes: a) como um ingrediente necessário em um sistema de informação de gestão, b), como uma característica única de uma empresa, c) como uma heurística ferramenta para os gestores para afinar os seus pensamentos, d), como uma descrição das principais competências e os recursos necessários para ser bem sucedido em um determinado mercado. (GRUNERT; ELLEGAARD, 1992)

Conforme Silva (2007) uma Matriz Importância-Desempenho foi proposta por Gianesi e Corrêa (1996), Hitt (2002) e Slack (1993), ao classificarem os critérios em três categorias: "ganhadores de pedido", "qualificadores" e "pouco relevantes". Os critérios "ganhadores de pedido" correspondem aos atributos extremamente importantes. Assim, são aqueles que o cliente se baseará para decidir qual vai ser o seu fornecedor, entre os qualificados. São esses critérios que contribuem para ganhar novos negócios. Portanto, incrementos no desempenho desses critérios acarretam em incrementos substanciais de benefício competitivo, indicando que qualquer esforço de melhoria nesse critério é recompensado. A segunda categoria, os “critérios qualificadores" são aqueles que a instituição deve atingir um nível mínimo de desempenho, pois irão qualificá-la a competir em determinado mercado. Esforços para aprimoramento no desempenho desses critérios somente são recompensados se o nível qualificador for atingido. A terceira categoria são os "critérios pouco relevantes", esforços de melhoria são sempre pouco compensados, pois não são critérios valorizados pelos clientes.

O verdadeiro fator chave de compra em um mercado, e os principais fatores percebidos pelo sucesso dos tomadores de decisão nas empresas que operam no mercado, será diferente. Uma série de mecanismos psicológicos resulta em afirmações falsas sobre as causas de sucesso em um mercado. Tanto os principais fatores reais de sucesso em um mercado, e da forma como são percebidos pelos decisores, são propícios para análise científica. Essa análise pode melhorar o desempenho dos decisores nesse mercado. As principais causas imediatas de sucesso em qualquer mercado são o valor percebido pelos clientes em um negócio de produtos, e os custos (em relação aos concorrentes) incorridos na elaboração deste valor. Como um bom negócio está na criação de valor aos clientes a baixos custos dependerá das competências e recursos da empresa. Assim, um fator chave de compra corresponde ao 
sucesso de habilidades ou recursos que uma empresa pode investir, o que, no mercado está a funcionar com o negócio. (GRUNERT; ELLEGAARD, 1992)

Os fatores-chave de compra diferem das competências básicas e de recursos, que são pré-requisitos para ser vencedor em um mercado, mas não explicam as diferenças no valor criado e os custos incorridos. Os fatores-chave de compra diferem em sua inconstância, ou seja, na medida em que os concorrentes podem emular eles. Os principais fatores sucesso podem ser medidos através de entrevistas semi-estruturadas com os tomadores de decisão das empresas que seguem um procedimento de progressão. (GRUNERT; ELLEGAARD, 1992)

\section{CONCLUSÕES}

Como já foi dito anteriormente, o objetivo do deste artigo é verificar os fatores críticos de sucesso para cursos de graduação presenciais e a distância. Assim, identificou-se que os FCS comuns nas pesquisas realizadas pelos autores que embasara teoricamente este trabalho, para um curso de ensino presencial são: Localização geográfica (Proximidade da faculdade/universidade de sua casa ou trabalho), Tradição da instituição (Tradição e status da instituição de ensino), Imagem da organização (Reputação do curso e da faculdade/universidade), Garantia de reconhecimento do curso (Avaliação do MEC do curso oferecido pela instituição de ensino), Valor de mensalidade menor que a concorrência (Valor da mensalidade), Infra-estrutura (Infra-estrutura e instalações da faculdade/universidade), Campanha publicitária periódica (Campanha de marketing da faculdade/universidade), Serviços de secretaria e de pessoal (Atendimento dos funcionários da faculdade/universidade), Qualificação do corpo docente (Qualidade da faculdade/universidade no ensino/aprendizado), Atualização do corpo docente (Corpo de professores do curso escolhido), Interação da coordenação com o corpo discente, Integração dos alunos com a instituição, e Metodologia aplicada à realidade do mercado de trabalho, Atividades em sala de aula e fora dela de simulação da vida real. No tocante aos cursos a distância, temos como FCS: Flexibilidade no Estudo (flexibilidade de horários e locais), Acolhimento do aluno pelo professore (relação aluno/professor), Usabilidade do Sistema (facilidade em utilizar as tecnologias), Tecnologia (suporte tecnológico para resolução de dúvidas), Segurança (confiabilidade nas informações), Interação (relação entre os alunos no espaço virtual), Qualidade do Curso, e Reconhecimento pelo MEC.

Os fatores-chave de compra são derivados dos fatores críticos de sucesso. Desta feita, o desafio dos fatores chave de compra consiste em identificar quais são os atributos de valor 
que realmente são utilizados pelos compradores em seu processo de escolha. Isto porque a escolha pode variar em função de suas preferências pessoais associadas aos produtos e serviços disponíveis. Quando se trata de serviços, essa dificuldade é superior, já que suas características associadas à intangibilidade, variabilidade, inseparabilidade e perecibilidade aliadas aos riscos de uma decisão errada são maiores, podendo causar prejuízos. Pelo conjunto de características específicas dos serviços, estes passam por um processo de "compra comparada", no qual o consumidor despende muito esforço e tempo para comparar as diferentes alternativas de oferta, até escolher somente uma delas. Isto reforça a importância de uma oferta de valor diferenciada, que seja percebida pelos consumidores.

Assim, no tocante aos FCS relacionados a EaD identificados como fatores de Qualidade do Curso e Reconhecimento pelo MEC, os critérios de excelência mais conhecidos no Brasil são os relativos ao MEC (Ministério da Educação) - IGC (Índice Geral de Cursos da Instituição) e ENADE (Exame Nacional de Desempenho de Estudantes), o Guia do Estudante da Editora Abril e Critérios de Excelência da Você S/A podem ser considerados fatores críticos de sucesso que interferem diretamente na escolha do cliente final. É fundamental para os cursos de $\mathrm{EaD}$ o atendimento aos critérios mínimos aceitos para o sucesso organizacional.

\section{REFERÊNCIAS}

ARETIO, Garcia Lorenzo. La Educación a distancia y La UNED, Madri, 1996

CISLAGHI, Renato; LUZ FILHO, Sílvio Serafim da. Balanced Scorecard em Instituições Públicas do Ensino Superior: Benefícios, Limitações e Desafios. Anais., VI Colóquio Internacional sobre Gestão Universitária na América do Sul, Blumenau, 2006.

DIAS, S. R. et al. Gestão de marketing. São Paulo: Saraiva, 2003.

FERREIRA, Armando Leite. Painel: Tecnologias de Ensino a distância e seu Papel nas Escolas de Negócios. Enanpad, 2001.

GONÇALVES, Cáio Márcio; COLAUTO, Romualdo Douglas; BEUREN, Ilse Maria. Identificação dos Fatores Críticos de Sucesso em Instituição de Ensino Superior. Anais..., V Colóquio Internacional Sobre Gestão Universitária na América Do Sul, Mar Del Plata, 2005.

GRUNERT, Klaus G.; ELLEGAARD, Charlotte. The Concept of Key Success Factors: Theory and Method. MAPP working paper, n. 4, October, 1992.

GUIA DO ESTUDANTE. Guia do Estudante da Editora Abril. Disponível em: <guiadoestudante.abril.com.br> Acesso em: 01 de jun. de 2009.

MAIA, M.de C. e MEIRELLES, F. de S. Evasão nos Cursos a Distância e sua 
Relação com as Tecnologias de Informação e Comunicação, ANPAD, 2005.

MAINARDES, Emerson Wagner; DESCHAMPS, Marcelo; DOMINGUES, Maria José Carvalho de Souza. O Que Atrai Alunos para Cursos de Graduação em Administração? Anais..., VI Colóquio Internacional Sobre Gestão Universitária na América Do Sul, Blumenau, 2006.

MALETZ, Edison Afonso; SIEDENBERG, Dieter Rugart. A Gestão dos Fatores Críticos de Sucesso nas Incubadoras de Empresas da Região do Ruhr - Alemanha. Enanpad, 2007.

MASROM, Maslin; ZAINON, Othman; RAHIMAN, Rosdina. Critical Success in E-learning: An Examination of Technological and Institutional Support Factors. 2008 International Joint Conference on e-Commerce, e-Administration, e-Society, and e-Education (e-CASE 2008), Bangkok, Thailand, 2008.

MEC. Ministério da Educação. Disponível em: <www.mec.gov.br>. Acesso em: 01 de jun. de 2009.

MEYER JR, Victor; LOPES, Maria Cecília Barbosa; ZABLONSKY, Marcos José. A Gestão de Matrículas Como Estratégia de Sobrevivência: Um Estudo Comparado de Universidades Comunitárias. Anais..., IV Colóquio Internacional Sobre Gestão Universitária na América Do Sul, Blumenau, 2006.

OLIVEIRA, Selma Regina Martins; SANTOS, Elaine Maria dos; KALATIZIS, Adriana Cadalis. Suporte Metodológico para Aperfeiçoamento de Planejamento em EAD Utilizando Estilos de Aprendizagem, Inteligências Múltiplas e Competências Requeridas: Um Estudo Multi-Casos nos Cursos de Administração. EnEPQ, 2007.

ROCKART, J. F. Chief executives define their own data needs. Harvard Business Review, 1979.

SEABRA, Gerson dos Santos. Universidade Estácio de Sá: 1970 - 2000: Onze Fatores Críticos de Sucesso, Um Estudo de Caso. Dissertação de Mestrado. Universidade Estácio de Sá, 2006.

SELIM, Hassan, M. Critical success factors for e-learning acceptance: ConWrmatory factor models. Computers \& Education, n. 49, 2007.

SILVA, Solange Maria da. Desenvolvimento de um Método de Análise de Posicionamento Competitivo de Serviços Complexos Baseado na Estrutura de Preferência dos Consumidores. Tese de Doutorado, Universidade Federal de Santa Catarina, 2007.

VIANEY, J. A universidade virtual no Brasil: o ensino superior a distância no Brasil. Tubarão: Ed. Unisul, 2003

VOCÊ S/A. Critério de Excelência Você S/A. Disponível em: <www.vocesa.abril.com.br>. Acesso em: 02 de jun. de 2009. 